\title{
The reliability of free association responses
}

JOHN F. HALL

THE PENNSYLVANIA STATE UNIVERSITY

Free association responses were obtained from high and low frequency stimulus words for 61 Ss. Seven or 21 days later, Ss responded to the same stimulus material. Results indicated that neither word frequency nor interval between sessions influenced the number of identical responses nade by the $S$. Findings indicated that an $S$ will make the same response to the same stimulus word presented on two different occasions, about $50 \%$ of the time.

Starting with the general assumption that free association responses may be used as indicators of verbal habit strength, a number of investigators have been interested in how free associative structure influences learning, transfer, and recall (i.e. Russell \& Storms, 1955; Deese, 1959; Postman, 1961; Higa, 1963; Martin, 1964; Winegartner, 1964; Wicklund, Palermo, \& Jenkins, 1964). Few experimenters, however, have been concerned with the reliability of word association responses. Wells (1911) in an examination of practice effects in free association, obtained some data related to the problem, but the uniqueness of his experimental procedure and small $\mathrm{N}$ makes his study difficult from which to draw conclusions.

The present study was an attempt to investigate the reliability of word association responses as a function of: (a) the use of high and low frequency stimulus words, and (b) a 7 or 21 day period intervening between the first and second testing.

Method

The stimulus words consisted of 27 high frequency, six letter adjectives, and 27 low frequency six letter adjectives. High frequency words had a frequency count of 50 or more occurrences per million; low frequency words had a frequency count of 1 to 5 occurrences per million. All words were randomly selected from the Thorndike-Lorge Word Book of 30,000 Words (1944). Stimulus material was presented with a Revere automatic slide projector. Instructions emphasized that the $S$ was to provide the first response which came to mind. Each $\mathrm{S}$ was then presented with a few practice words in order to provide familiarity with the procedure. The 54 high and low frequency words were then presented in a random order. At the conclusion of the session, the $S$ was scheduled to return either 7 or 21 days later. During the second session $S$ was run through exactly the same procedure. Instructions acknowledged that the $\mathrm{S}$ was participating in a second session but stressed the fact that responses were to be "free."

Sixty-one Ss, obtained from an introductory psychology course, participated, with 31 Ss retested seven days after the first session while 30 Ss were retested a.fter 21 days.

\section{Results and Conclusions}

Sixty-one Ss responding to 54 words on each of two sessions provides 3294 test-retest responses. Of these, 132 were lost when the S blocked to the stimulus word when it was presented on one of the two sessions. Thus, 3162 responses make up the basic data.

A primary concern was to examine the number of responses made during the second session which were identical to those provided on the first. In making the identity of response classification, a response which was plural in form was considered to be identical to the singular. The mean number of identical responses for the varying conditions is presented in Table 1. Analysis of variance revealed that neither word frequency, interval between sessions, nor their interaction produced a significant effect. Summing over all groups, slightly less than $50 \%$ of the time, an S's response to a stimulus word will be the same on the second testing as that provided on the first.

An ad hoc analysis of the data was made in order to determine if those stimulus words which resulted in many Ss responding similarly on the first session would maximize identity of individual responding during the second session. To illustrate, $32 \mathrm{Ss}$ (of 61 ) made the response GOLD to the stimulus word SILVER; on the other hand, to the word SECRET, the most frequent response was QUIET which had an $\mathrm{N}$ of 5 . It might be assumed that many more identical responses would be made to SILVER than to SECRET-an assumption, of course, which rests on the frequently held position that group responding reflects individual habit strength. In order to test this assumption, a product moment correlation was computed between the number of common responses obtained from each of the stimulus words during the original testing, and the number of identical responses which were made to those words during the second session. The obtained $r$ was .01 , which suggests that this variable also does not covary with identity of responding.

A second area of concern was related to the nature of the nonidentical responses. Here, interest was directed in examining whether or not these nonidentical responses could be found in the original response hierarchy. Hierarchies were compiled, based upon the responses made by the 61 Ss during the first testing.

Table 1. Mean Number of Identical Responses Made as a Function of Word Frequency and Time Between Testing

\begin{tabular}{rrrr} 
& $N$ & Low Frequency & High Frequency \\
\hline 7 Days & 31 & 12.35 & 13.48 \\
21 Days & 30 & 11.57 & 11.60 \\
\hline
\end{tabular}


Table 2. Mean Number of Nonidentical Responses Found Within the Original Response Hierarchy

\begin{tabular}{rccc} 
& $N$ & Low Frequency & High Frequency \\
\hline 7 Days & 31 & 6.13 & 6.90 \\
21 Days & 30 & 7.07 & 8.37 \\
\hline
\end{tabular}

Each nonidentical response made during the second testing was then classified as to whether or not it fell within the hierarchy-that is, whether or not it was the same as one of the words comprising the original response hierarchy list. Tables 2 and 3 provide this information, broken down into high and low frequency words and interval between sessions. Again, differences among groups were not significant.

Summing over groups, a little more than $27 \%$ of the responses made on the second testing fall within the response hierarchy, while approximately $25 \%$ fall outside the hierarchy. It should be noted that these percentage values are dependent upon the number of Ss which make up the sample. As sample size increases, a larger number of words will comprise the response hierarchy, thus increasing the probability that more

Table 3. Mean Number of Nonidentical Responses which were Found Outside the Original Response Hierarchy

\begin{tabular}{rrrr} 
& N & Low Frequency & High Frequency \\
\hline 7 Days & 31 & 6.45 & 5.97 \\
21 Days & 30 & 7.20 & 6.57 \\
\hline
\end{tabular}

nonidentical responses will be found within the response hierarchy rather than without.

Our findings indicate, then, that in the free association situation an $\mathrm{S}$ will make the same response to the same stimulus word presented on two different occasions, about $50 \%$ of the time. This value presumably provides sufficient stability to enable investigators to utilize word association responses in their experimental analysis of learning, transfer, and retention. Such identity of responding does not appear to be influenced by either the use of high or low frequency stimulus words, or by the interval of time (up to three weeks) between sessions.

\section{References}

Deese, J. Influence of inter-item associative strength upon immediate free recall. Psychol. Rep., 1959, 5, 305-312.

Higa, M. Interference effects of intralist word relationships in verbal learning. $J$. verbal Learn. verbal Behav., 1963, 2, 170-175.

Martin, J. G. Associative strength and word frequency in pairedassociate learning. $J$. verbal Learn. verbal Behav., 1964, 3, 317-320.

Postman, L. The effects of language habits on the acquisition and retention of verbal associations. $J$. exp. Psychol., 1962, 64, 7-19.

Russell, W. A., \& Storms, L. H. Implicit verbal chaining in paired associate learning. J. exp. Psychol. 1955, 49, 287-293.

Thorndike, E. L. \& Lorge, I. The Teacher's Word Book of 30,000 Words. New York: Teacher Coll., Columbia Univ., 1944.

Wicklund, D. A., Palermo, D. S., \& Jenkins, J. J. The effects of associative strength and response hierarchy on paired-assocjate learning. J. verbal Learn verbal Behav., 3, 413-420.

Weingartner, $\mathbf{H}$. The free recall of sets of associatively related words. J. verbal Learn. verbal Behav., 1964, 3, 6-10.

Wells, F. L. Practice effects in free association. Amer. J. Psychol., 1911, 22, 1-13. 